\title{
Mechanical Properties and Dimensional Stability of Rigid PVC Foam Composites Filled with High Aspect Ratio Phlogopite Mica
}

\author{
Murtatha M. Jamel, Parisa Khoshnoud, Subhashini Gunashekar, Nidal Abu-Zahra* \\ Materials Science and Engineering Department, University of Wisconsin-Milwaukee, Milwaukee, USA \\ Email: ${ }^{\text {nidal@uwm.edu }}$
}

Received 15 May 2015; accepted 5 June 2015; published 8 June 2015

Copyright @ 2015 by authors and Scientific Research Publishing Inc.

This work is licensed under the Creative Commons Attribution International License (CC BY).

http://creativecommons.org/licenses/by/4.0/

(c) (i) Open Access

\begin{abstract}
High aspect ratio Phlogopite mica was used to enhance the dimensional stability and mechanical properties of extruded rigid Polyvinyl Chloride (PVC) foam. Mica was added to rigid PVC compound at different concentrations ( 0 - $20 \mathrm{wt} \%$ ) and processed using a single screw profile extruder. PVC foam-Mica composites were characterized for their dimensional stability, and structural, thermal, and mechanical properties. Experimental results showed that the dimensional stability increased by $44 \%$ and heat resistance of the samples improved as the amount of mica increased in the composites. The storage modulus and tensile strength of the composites were also enhanced with the addition of mica. However, increasing the concentration of mica had no significant effect on the impact and flexural properties of the composites. SEM micrographs show good dispersion and orientation of the mica flakes along the cell walls of the PVC foam. Overall, the platy structure and physical properties of mica seemed to have played an important role in providing good interfacial bonding with the cell membranes of the foam, thus enhancing the dimensional stability of the PVCMica foam composites.
\end{abstract}

\section{Keywords}

Polyvinyl Chloride, PVC Foam, PVC Composites, Polymer Composites, Mica Composites, Reinforced Polymers

\footnotetext{
${ }^{*}$ Corresponding author.
} 


\section{Introduction}

Polymer foams are a unique class of materials that are widely used due to their light weight, low cost, and good formability along with load bearing and insulation capabilities. The cellular structure of the foam determines its mechanical and physical properties, and hence its performance and applications [1] [2]. Rigid Polyvinyl Chloride (PVC) foams and their composites have been used as an excellent replacement for wood in the building material industry in the form of profiles, sheets, and pipes due to their low cost, low density, fire retardancy, and high insulation and damping properties. However, rigid PVC foams lack adequate dimensional stability when they are exposed to high and low temperatures. Certain applications of PVC foam products require excellent dimensional stability; such as in exterior molding, siding, decking and railing applications. Solid fillers, such as calcium carbonate, talc, glass fibers, carbon fibers, and wood fibers, have been reported as effective PVC reinforcement additives in many publications [3]-[5]. The selection process for an effective reinforcement filler depends on its compatibility with the polymer matrix and the desired relationship among structure, property, and performance of the composite.

Mica is a general term applied to a group of complex aluminosilicates containing potassium, magnesium, iron, sodium, fluorine and/or lithium. Each member of the group exhibits different physical properties, but all form flat six sided monoclinical crystals with a definite cleavage in the direction of large surface, allowing them to split easily into optically flat films as thin as $1 \mu \mathrm{m}$. Phlogopite mica, a hydrated silicate of potassium and magnesium, is associated with metamorphosed limestone and ultrabasic rocks, particularly hydrothermal veins formed through metasomatism of magnesium-rich rocks as well as ultrabasic and carbonatite ring intrusions associated with ancient shield areas [6].

Micas are characterized by a sheet or plate like structure, which because of its excellent basal cleavage enables particles of high aspect ratio to be produced. These lamellar particles are flexible, tough, and relatively soft, and have a low coefficient of thermal expansion, exceptional electrical properties and excellent chemical resistance. The high aspect ratio of the platy particles provides an excellent balance of mechanical, thermal and dimensional properties when used as functional filler in plastics providing increased stiffness, high temperature performance, improved scratch resistance, acoustic damping properties, lower coefficient of linear thermal expansion (CLTE) and improved dimensional stability [6].

Based on the literature review, there is very limited work on the effect of mica on the dimensional stability and mechanical properties of polymer foams. Otherwise, the use of mica as reinforcing filler in non-foam polymer composites has been studied and reported extensively [7]. Zhao et al. [8] studied the effect of using (0\% $50 \%$ ) mica on the mechanical properties of polypropylene-based glass-mat thermo-plastic (GMT) composites; they reported improvement in the tensile and flexural strengths of the composites at lower mica content (10\%). The same properties were compromised at higher mica contents, e.g., 20\% - 50\%. The impact strength was maximized at $20 \mathrm{wt} \%$ mica content. Raj et al. [9] studied the effect of heat exposure on the mechanical and thermal properties of mica, glass fiber, and wood fiber reinforced low density polyethylene (LDPE); they reported maximum improvement in the dimensional stability and tensile modulus in the case of mica reinforced LDPE. Liang et al. [10] studied the effect of mica on the mechanical and thermal properties of high density polyethylene (HDPE) at different mica contents $(5 \%, 10 \%$, and 15\%). They reported improvements in the tensile and yield strengths and deterioration in the impact strength of the composites.

Canova et al. [11] examined the use of mica and glass fibers in Polypropylene (PP) composites; they used $20 \%-40 \%$ of total filler content as a combination of mica and glass fibers. The dimensional stability was reported to improve by adding mica alone; the linear shrinkage at $49^{\circ} \mathrm{C}$ was measured to be $0.64 \%$ at $40 \%$ mica compared with $1.6 \%$ at $20 \%$ mica. On the other hand, the ductility and flexural strength decreased by increasing the mica content between $20 \%$ and $40 \%$. Souza et al. [12] studied the thermal properties of mica filled poly(lactic acid) composites at different concentrations of mica $(2.5 \%, 5 \%$, and $7.5 \%)$; it was reported that the thermal stability was improved by increasing the mica content. Sreekanth et al. [13] worked on reinforcing extruded polyester composites with mica $(0-40 \mathrm{wt} \%)$. The rigidity and thermal properties of the extruded samples were enhanced by adding mica, whereas the impact strength deteriorated at higher mica contents. Similarly, Marshall et al. [14] reported an increase in the tensile modulus of PP, HDPE, and PVC composites with the addition of mica, while maintaining the original levels of tensile strength.

Jiang et al. [15] reviewed the effect of adding mica and glass fibers to PVC-Wood foam composites, using chemical blowing agents. They cited improvement in the mechanical properties of the foam composites by add- 
ing mica or glass fibers. Deshmukh et al. [16] examined the effect of different parameters, such as particle size, concentration, and surface treatment on the mechanical properties of reinforced PVC composites (non-foam). They reported poor dispersion at high contents of mica which led to phase separation of the mica agglomerates in the polymer matrix. The goal of this work is to study the effect of high aspect ratio mica on the dimensional stability and mechanical properties of extruded rigid Polyvinyl Chloride (PVC) foam.

\section{Experimental}

\subsection{Materials}

Rigid PVC resin was purchased from Shintech, USA; it has an inherent viscosity of 0.74 (ASTM D1243); bulk density of $36.3 \mathrm{lb} / \mathrm{ft} 3$ (ASTM D 1895), and maximum volatiles of 0.12\% (ASTM D3030). A commercially available thermal stabilizer, Thermolite T-137, and processing aids, Plastistrength P530 and P770, were provided by Arkema, USA. Other ingredients used in preparing the samples are Lubricants Loxiol 2986 and 2987 produced by Oleochemicals; paraffin wax Petrac 215 produced by Ferro Corp.; Calcium Stearate COAD 10 produced by Norac Corp.; chemical blowing agents Azodicarbonamide (ADC) produced by Season Corp.; and Sodium Hydrogen Carbonate (FICEL SBH) produced by Hughes Polymer Additives Corporation. The specific content of each ingredient is considered proprietary; however the amount of each ingredient follows a common formulation used in making rigid PVC foams. Phlogopite Mica PW80 was used as received from LKAB Minerals, Inc., USA. Figure 1 shows the platy structure of mica. The particle size distribution and chemical analysis of PW80 phlogopite mica are shown in Tables 1 and Table 2, respectively.

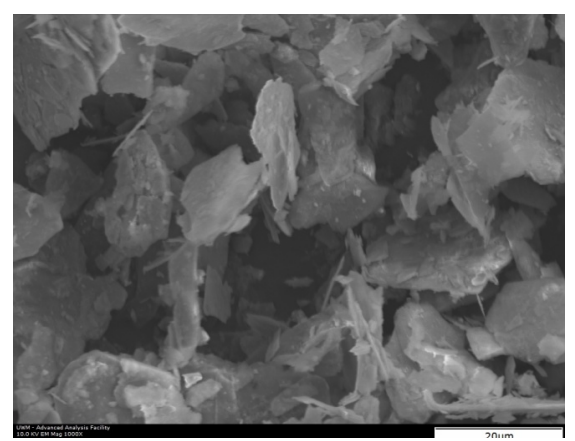

Figure 1. SEM micrograph of mica platelets as received at 1000×.

Table 1. Particle size distribution of phlogopite mica PW80 [6].

\begin{tabular}{ccc}
\hline BS Mesh No. & Sieve Aperture (Microns) & Cumulative \% Passing \\
\hline 60 & 250 & $99.9-100$ \\
100 & 150 & $96-100$ \\
350 & 45 & $70-95$ \\
& Loose Bulk Density & $0.15-0.35 \mathrm{~kg} / \mathrm{lt}$ \\
\hline
\end{tabular}

Table 2. Chemical analysis of phlogopite mica PW80 [6].

\begin{tabular}{cc} 
Chemical Analysis & \% by Weight \\
\hline Silicon as $\mathrm{SiO}_{2}$ & $40-42$ \\
Magnesium as $\mathrm{MgO}$ & $20-26$ \\
Potassium as $\mathrm{K}_{2} \mathrm{O}$ & $10-11$ \\
Aluminum as $\mathrm{Al}_{2} \mathrm{O}_{3}$ & $9-11$ \\
Iron as $\mathrm{Fe}_{2} \mathrm{O}_{3}$ & $3-11$ \\
Loss on Ignition at $1000^{\circ} \mathrm{C}$ & $1-3$ \\
\hline
\end{tabular}




\subsection{Sample Preparation}

PVC foam compounds were prepared using a high shear mixer (Gunther Pepenmeier, Machinen-u. Detmoid, Type: TSHK). Initially, the PVC resin was added to the mixer at room temperature. Then, the stabilizer was added at $52^{\circ} \mathrm{C}$, mica and processing aids were added at $58^{\circ} \mathrm{C}$. Finally, the lubricants and the blowing agents were added at $66^{\circ} \mathrm{C}$. When the temperature reached $100^{\circ} \mathrm{C}$, the compound was collected from the mixer and allowed to cool down to room temperature before extrusion.

The compounds were extruded using a 1.25 inch, 20:1 (L/D) single screw extruder (Themoplast Extrusion Machine) at a screw speed of $60 \mathrm{rpm}$. The heating zone temperatures were in the range of $158^{\circ} \mathrm{C}$ to $175^{\circ} \mathrm{C}$. A rectangular profile die was used to extrude the samples. The extruded stream was air cooled prior to feeding through an aluminum sizer $\left(1 " \times 0.28^{\prime \prime}\right)$ placed in a vacuum chilled water tank. Finally, the extruded stream is cut into 12" pieces using an automated cutter. The composite formulations are listed in Table 3.

\subsection{Characterization}

\subsubsection{Thermal Characterization}

Thermal properties of the foam composites were analyzed using: 1) TA Instrument SDT 2960 thermo-gravimetric analysis equipment (TGA) in the temperature range of $25^{\circ} \mathrm{C}$ to $800^{\circ} \mathrm{C}$ at a heating rate of $10^{\circ} \mathrm{C} / \mathrm{min}$ under argon atmosphere; 2) Differential Scanning Calorimetry (DSC) measurements using TA Q2000 analyzer (TA Instruments, USA). Foam composite samples weighing 5 to $10 \mathrm{mg}$ were heated in standard aluminum pans in the temperature range of $25^{\circ} \mathrm{C}$ to $260^{\circ} \mathrm{C}$ at a heating rate of $10^{\circ} \mathrm{C} / \mathrm{min}$.

Dynamic Mechanical Analysis (DMA) was performed on TA Instrument Q800 to evaluate the viscoelastic properties (storage modulus, loss modulus, and $\tan \delta$ ) of composites in the solid state. A three-point bending mode was used at a test temperature range of $25^{\circ} \mathrm{C}$ to $120^{\circ} \mathrm{C}$ at a constant heating rate of $3^{\circ} \mathrm{C} / \mathrm{min}$ and a dynamic force at a frequency of $1 \mathrm{~Hz}$.

The dimensional stability of the foam composites was analyzed according to the American Architectural Manufacturers Association (AAMA) standards. Extruded samples were heated in an oven at $82^{\circ} \mathrm{C}$ for 30 minutes. The original dimensions of the foam composites were $12^{\prime \prime} \times 1 " \times 0.28^{\prime \prime}$. The change in length was measured after 4 hours and the percent shrinkage was determiend according to Equation (1), where $l_{0}$ and $l_{f}$ are the initial and final lengths; respectively:

$$
\% \text { Shrinkage }=\frac{l_{0}-l_{f}}{l_{0}} \times 100
$$

Heat resistance of the composites was also analyzed according to AAMA standards. Extruded samples were heated in an oven at $141^{\circ} \mathrm{C}$ for 30 minutes. The original dimensions of the foam composites were $12^{\prime \prime} \times 1 " \times$ $0.28^{\prime \prime}$. The samples were cooled for 4 hours and a visual inspection was done to determine the presence of any flaws or distortion in the samples.

\subsubsection{Mechanical Properties}

Tensile properties were determined using Instron 3365 universal testing machine on rectangular specimens measuring $12^{\prime \prime} \times 1 " \times 0.28$ " at a crosshead speed of $0.5 \mathrm{in} / \mathrm{min}$. Flexural properties were determined using Instron 3365 with a three-point bending test set-up on rectangular specimens measuring 8 " $\times 1$ " $\times 0.28^{\prime \prime}$ at a crosshead speed of $0.5 \mathrm{in} / \mathrm{min}$. The span length was kept at 4 inches. The flexural stress and strains were calculated using Equations (2)-(3):

Table 3. PVC-mica foam composites formulation.

\begin{tabular}{|c|c|c|c|c|c|}
\hline Mica (wt\%) & PVC Resin (wt\%) & Stabilizer (wt\%) & Blowing Agents (wt\%) & Lubricants (wt\%) & Processing Aid (wt\%) \\
\hline 0 & 92.5 & & & & \\
\hline 5 & 87.5 & & & & \\
\hline 10 & 82.5 & 0.85 & 0.5 & 0.6 & 6 \\
\hline 15 & 77.5 & & & & \\
\hline 20 & 72.5 & & & & \\
\hline
\end{tabular}




$$
\begin{gathered}
\sigma_{f}=\frac{3 P L}{2 b d^{2}} \\
\varepsilon_{f}=\frac{6 D d}{L^{2}}
\end{gathered}
$$

where, $\sigma_{f}$ and $\varepsilon_{f}$ are the respective flexural stress and strain at the midpoint, and $P, L, b, d, D$ are the load, span length, specimen width, specimen thickness and midpoint deflection; respectively. The flexural strength was determined using the maximum stress value recorded before sample fracture and flexural modulus was determined by the slope of the initial linear region of the stress-strain curve.

Charpy impact properties were determined using Tinus Olsen impact testing machine (model IT 504) according to ASTM D 6110. Four samples of each composite were tested. The dimensions of the impact testing samples were $5^{\prime \prime} \times 0.5^{\prime \prime} \times 0.28^{\prime \prime}$ with a $45^{\circ}$ notch at the middle.

\subsubsection{Scanning Electron Microscopy}

Topcon SM-300 SEM was used for imaging and microstructural analysis of the extruded PVC-Mica foam composites. The specimens were fractured in liquid nitrogen and coated using a sputter coater to minimize the charging effect and to improve the conductivity of the samples prior to analysis.

\section{Results and Discussion}

\subsection{Thermal Properties}

Dimensional stability of the foam composites were assessed as a percentage of linear shrinkage of the extruded foam composites when heated to $82^{\circ} \mathrm{C}$ for 30 minutes; as shown in Figure 2. It is evident that increasing the percentage of mica reduces the thermal shrinkage of the PVC-mica composites from an initial value of $3.4 \%$ to $1.9 \%$ in samples reinforced with $20 \%$ mica, which accounts for a net reduction of $44 \%$. Since mica has a lower thermal expansion coefficient than PVC, higher interaction between mica platelets and the foam matrix improves dimensional stability of the composites. The reduction in shrinkage with the addition of mica is nonlinear. Samples containing 5\% mica barely show any improvement in dimensional stability when compared to the pristine PVC foam. However, increasing the amount of mica in the composite samples decreases the shrinkage in the samples; the highest drop in shrinkage can be observed as the amount of mica is increased above $15 \%$ in the samples. It is hence expected that adding mica above $20 \%$ in the composites can further reduce the shrinkage due to the high dimensional and thermal stability of mica itself [6] [7].

Heat resistance was evaluated qualitatively by visual inspection for surface flaws and shape distortion of the extruded samples after heating and cooling cycles. Although, the test samples did not show any flakes or cracks on the surface, some distortion was observed on the edges as shown in Figure 3.

Although increasing the amount of mica in the composites decreased the shape distortion due to the high thermal resistance of mica, the addition of mica did not seem to affect the glass transition temperature $\left(\mathrm{T}_{\mathrm{g}}\right)$ of the composites. The $\mathrm{T}_{\mathrm{g}}$ remained around $83^{\circ} \mathrm{C}$ as shown in Table 4 , however, the gelation of the PVC-mica composites was found to increase and was above $98 \%$. This indicates good dispersion of the plasticizer into the PVC resin which may have improved the dispersion of mica in the foam matrix [17].

The results from TGA analysis of PVC-Mica foam composites are presented in Figure 4. The average Primary Degradation Temperature (PDT) of the foam composites begins around $273^{\circ} \mathrm{C}$, and the average Secondary Degradation Temperature (SDT) is around $443^{\circ} \mathrm{C}$. As shown in Table 5, increasing the amount of Mica increases the SDT of the composites, which means that it takes more energy to break the hydrocarbon backbone of the polymer matrix [18] [19]. On the other hand, PDT of the composites, which indicates the decomposition of chlorine from the polymer chains, decreases slightly by increasing the Mica content. This can be attributed to the higher thermal conductivity of Mica, which results in faster heat transfer into the PVC matrix lowering the thermal degradation temperatures. The residual weight at $800^{\circ} \mathrm{C}$ was found to increase as the amount of mica increased in the composites, which clearly indicates the presence of higher amounts of the inorganic filler in the matrix [19], as shown in Table 5.

Thermo mechanical properties of the PVC-mica composites were determined by DMA analysis. Variations with temperature in the storage modulus $\left(E^{\prime}\right)$, which represents the elastic behavior of the composites, and the loss modulus (E"), which represents the viscous behavior, are shown in Figure 5 and Figure 6; respectively. The 


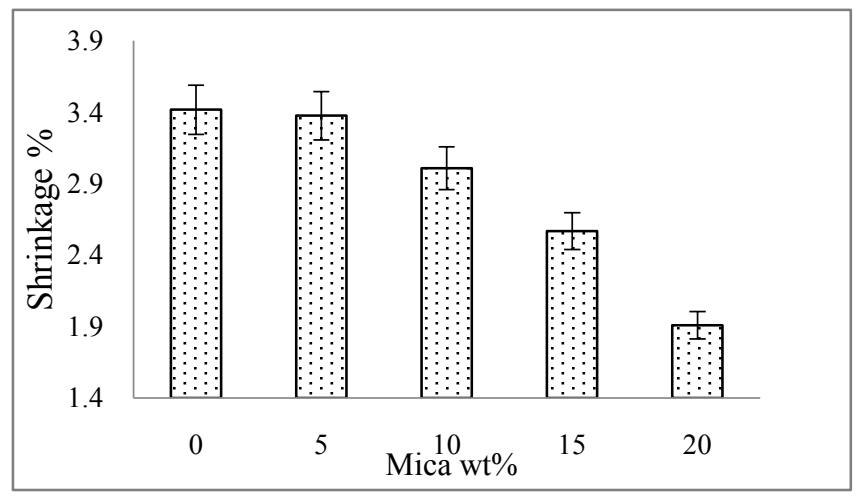

Figure 2. Dimensional stability of PVC-mica foam composites.

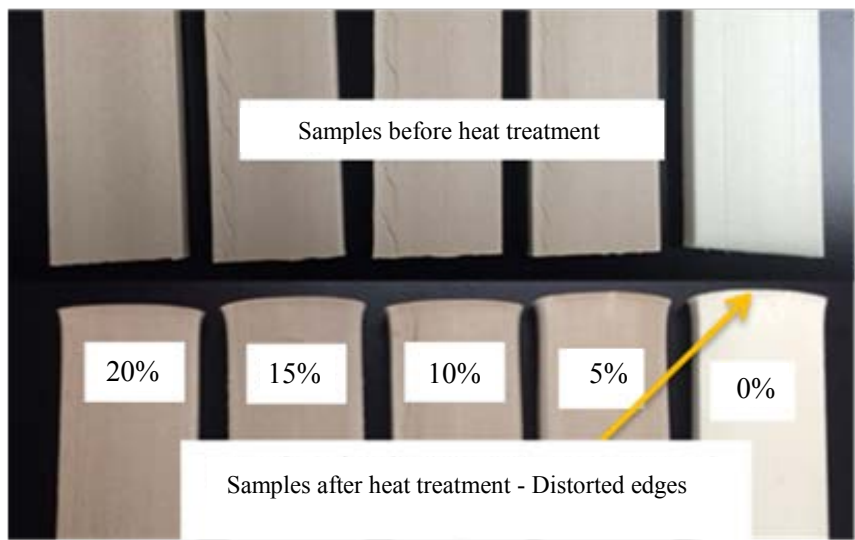

Figure 3. Distortion in PVC foam-mica composites before and after heat treatment.

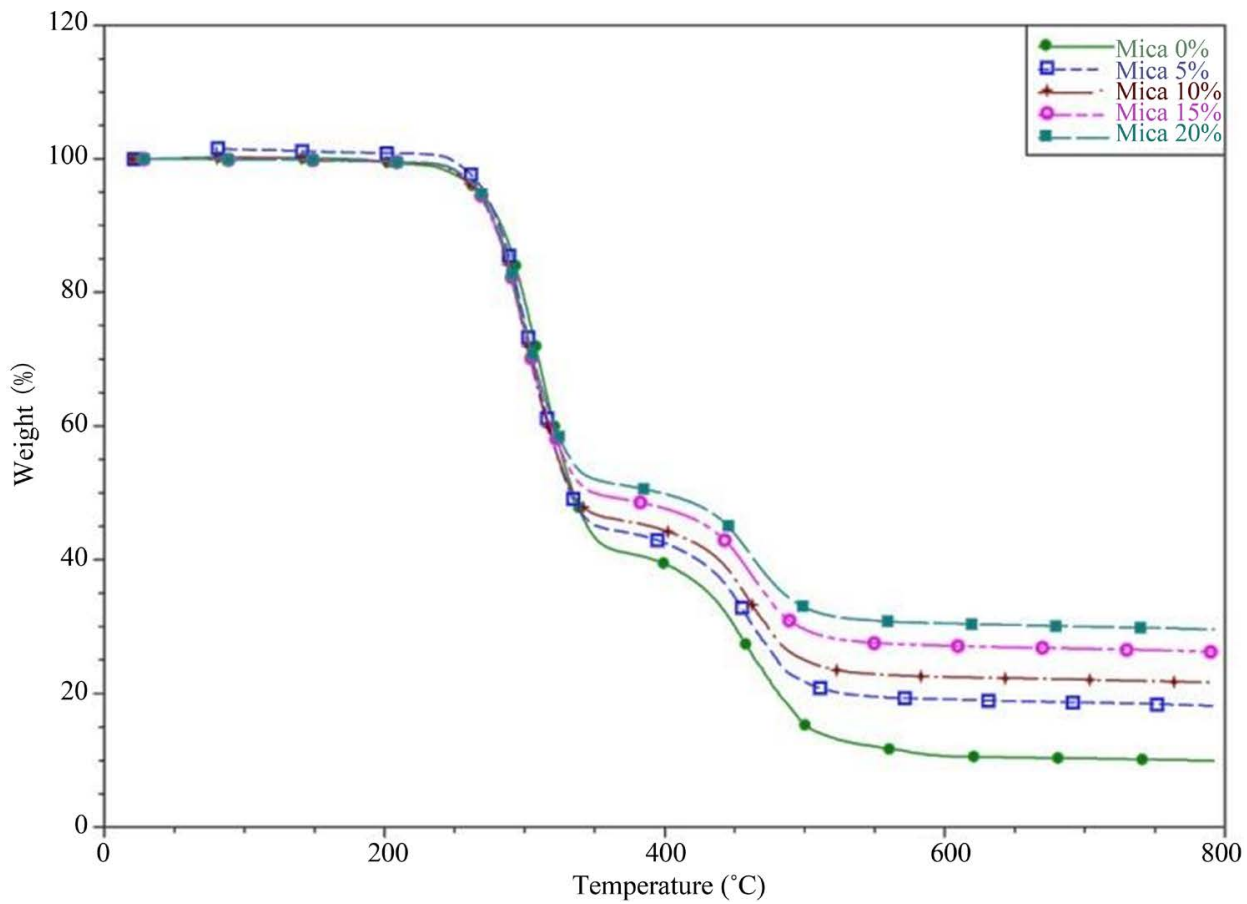

Figure 4. TGA analysis for PVC-mica foam composites, the curves are labeled with respect to the value of residual weight at $800^{\circ} \mathrm{C}$ from the top to bottom. 
Table 4. Glass transition temperatures and gelation of PVC-mica foam compositesdetermined by DSC.

\begin{tabular}{cccccc}
\hline Sample & $0 \%$ & $5 \%$ & $10 \%$ & $15 \%$ & $20 \%$ \\
\hline $\mathrm{T}_{\mathrm{g}}\left({ }^{\circ} \mathrm{C}\right)$ & 82 & 84 & 83 & 83 & 83 \\
Gelation $(\%)$ & 98 & 99 & 99 & 99 & 99 \\
\hline
\end{tabular}

Table 5. Primary and Secondary Decomposition Temperature (PDT and SDT) of PVC-mica foam composites.

\begin{tabular}{ccccc}
\hline Mica wt\% & PDT $\left({ }^{\circ} \mathbf{C}\right)$ & Weight Loss at PDT $(\%)$ & SDT $\left({ }^{\circ} \mathbf{C}\right)$ & Weight Loss at SDT (\%) \\
\hline $\mathbf{0}$ & 279.4 & 40 & 442.3 & 10 \\
$\mathbf{5}$ & 273.8 & 45 & 442.8 & 25 \\
$\mathbf{1 0}$ & 271.8 & 48 & 443.6 & 28 \\
$\mathbf{1 5}$ & 271.2 & 50 & 445.2 & 32 \\
$\mathbf{2 0}$ & 270.7 & 55 & 444.4 & 35 \\
\hline
\end{tabular}

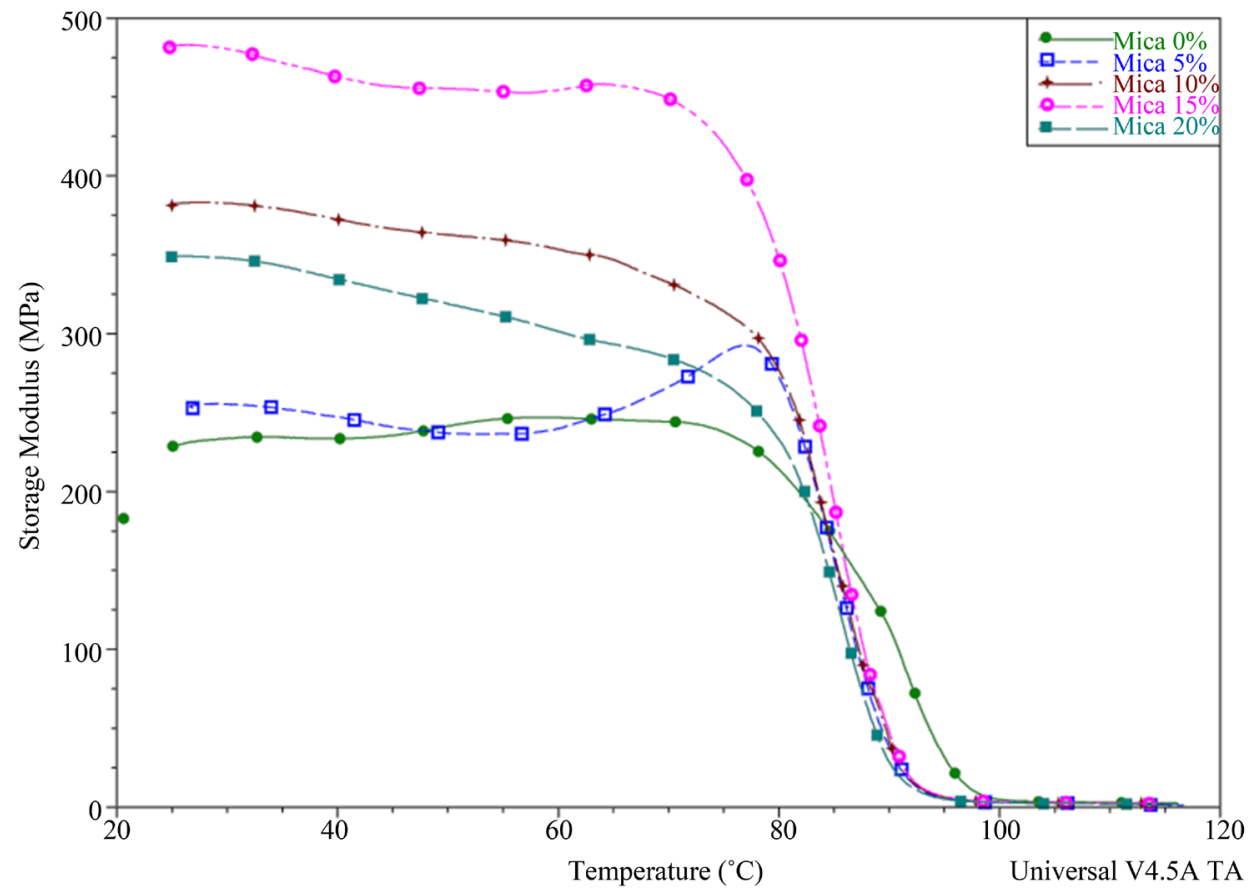

Figure 5. Storage Modulus (E') of PVC-Mica foam composites.

magnitude of $E^{\prime}$ and the peak intensity of $E^{\prime \prime}$ increase with the addition of mica up to $15 \%$. This may be attributed to the enhancement in the energy dissipation ability in the presence of solid filler in the polymer matrix and the increase in the polymer-filler and filler-filler slippages at the $T_{g}$ [19] [20]. However, in samples reinforced with $20 \%$ mica, the magnitude of $\mathrm{E}^{\prime}$ decreases; this may be attributed to the agglomeration of mica at higher concentrations. The agglomeration of mica may lead to higher friction between the particles and less interaction between the reinforcing phase and the host matrix, which may consequently reduce the energy dissipation in the reinforced polymer matrix [21].

In comparison to all the samples, a significant change in the elastic and viscous properties were observed in samples reinforced with $15 \%$ mica with respect to the pristine PVC foam sample; the storage modulus was found to increase from $225 \mathrm{MPa}$ to $480 \mathrm{MPa}$ at room temperature while the loss modulus (E") had increased from $52 \mathrm{MPa}$ to $88 \mathrm{MPa}$ around the glass transition temperature of the samples. This indicates that the rigidity at room temperature and flow-ability around the $\mathrm{T}_{\mathrm{g}}$ of the PVC foam composites improve as the amount of mica is 


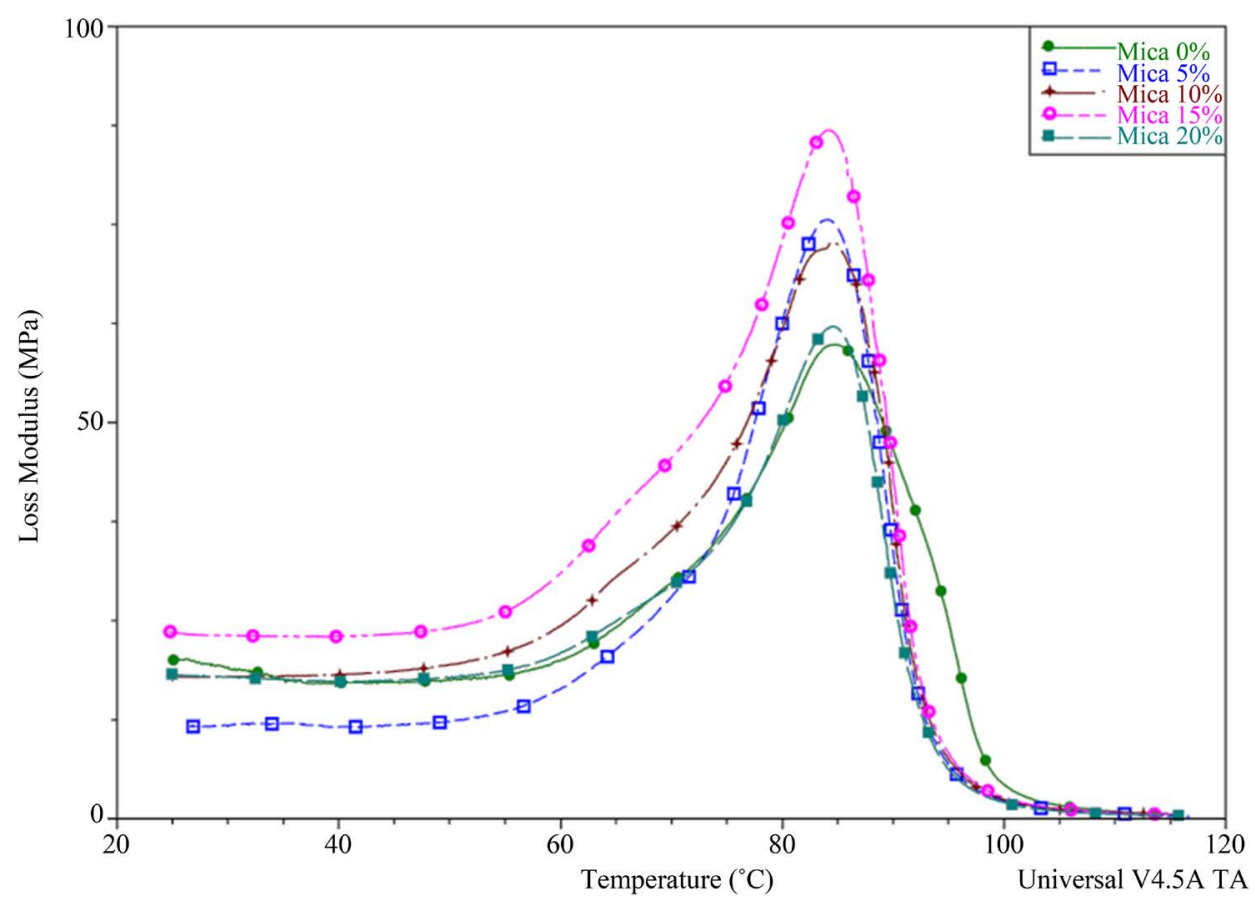

Figure 6. Loss modulus (E") of PVC-mica foam composites.

increased up to $15 \%$ in the composites. The platy structure and chemical composition of mica can be attributed to this behavior. It is also observed that a further increase in the loading of mica beyond $15 \%$ does not improve the viscoelastic properties of the composites. One can speculate that particle agglomeration at higher loadings may hinder the effect of the reinforcing filler to further improve the viscoelastic properties.

\subsection{Mechanical Properties}

The effect of mica on the ultimate tensile strength (UTS) of the composite foams is shown in Figure 7. Composite samples reinforced with $10 \%$ mica showed the highest UTS value of all the composites and the UTS started to decrease beyond this loading. The improvement in the UTS of the composites in comparison to the pristine polymer may be attributed to higher dispersion of mica platelets in the cell walls at lower concentrations and the good bonding between the platelets and the polymer matrix [20] [21]. However, at higher concentrations of mica, i.e. above $15 \%$, the brittleness of the mica flakes combined with higher agglomeration in the cell walls may have led to a decrease in the overall strength of the composite foams.

The ductility of the PVC-Mica composites, measured by the extension at break, is shown in Figure 8 . The effect of mica on the ductility of the composite foams follows the same pattern and is similar to its effect on the tensile strength of the foams. The maximum ductility was observed in samples reinforced with $10 \%$ mica, whereas the ductility started to decrease at higher mica concentrations. The reinforcement of cell walls with mica provides additional strength and ductility under loading, thus delaying the rupture of the cell walls. This may be due to the lamellar structure of the mica flakes combined with the preferred orientation of the flakes along the cell walls improves the surface bonding with the polymer matrix [10] [13] [16]. The maximum improvement observed in samples with lower mica content may be due to the higher dispersion of the mica flakes in the cell walls which may have resulted in better surface bonding with the polymer phase. However, at higher concentrations of mica, the particles may have started to agglomerate in the cell walls and formed a separate solid phase which might have lowered the surface bonding with the polymer phase. Consequently, this might have lowered the strength and ductility of the composites at the cell walls causing them to rupture.

Other mechanical properties of the PVC-mica composites; such as flexural and impact strengths, are summarized in Table 6. It can be noticed that the presence of mica does not seem to improve the flexural strength of the composites. This can be attributed to the orientation of the mica flakes along the cell walls which improves the strength of the composites up to a certain extent under tension, but has detrimental effect on the strength of 


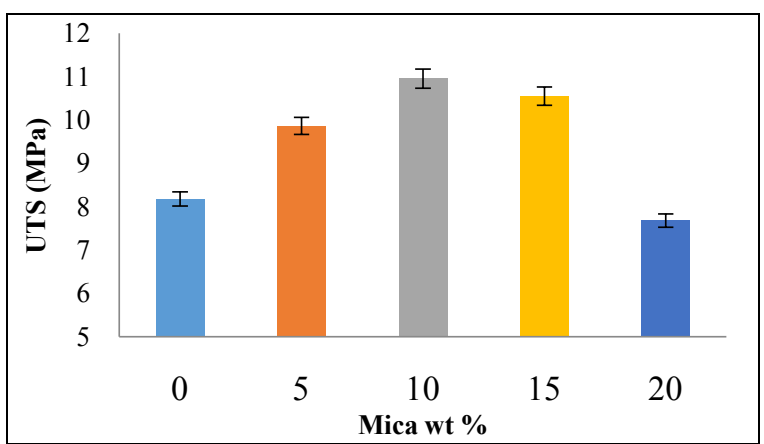

Figure 7. Ultimate Tensile Strength (UTS) of PVC-mica foam composites.

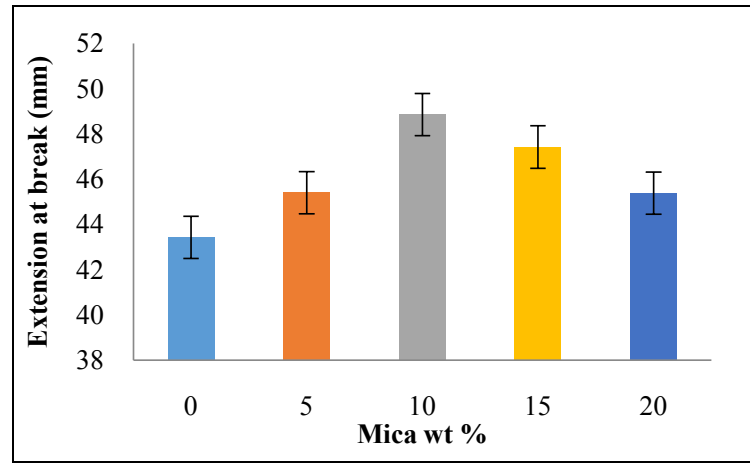

Figure 8. Ductility of PVC-mica composites.

Table 6. Mechanical properties of PVC-mica foam composites.

\begin{tabular}{ccccc}
\hline Mica wt\% & UTS $(\mathrm{MPa})$ & Extension at Break $(\mathrm{mm})$ & Flexural Strength $(\mathrm{MPa})$ & Impact Strength $(\mathrm{J} / \mathrm{m})$ \\
\hline $\mathbf{0}$ & 8.17 & 43.43 & 17.26 & 30.13 \\
$\mathbf{5}$ & 9.86 & 45.39 & 17.01 & 30.11 \\
$\mathbf{1 0}$ & 10.95 & 48.85 & 17.25 & 29.56 \\
$\mathbf{1 5}$ & 10.54 & 47.41 & 17.33 & 26.07 \\
$\mathbf{2 0}$ & 7.67 & 45.38 & 17.19 & 22.06 \\
\hline
\end{tabular}

the composites under compression loading. Since the test samples under flexure loading experience tensile stresses as well as compression stresses on opposite sides, the net improvement of mica on the overall flexural strength is insignificant [13]. The impact strength of the PVC-mica composites started to deteriorate with the addition of mica. This may be attributed to the increased rigidity of the polymer matrix, which is amplified at higher concentrations due to particle agglomeration, which promotes brittle fracture under impact loading [15] [16] [22].

\subsection{Microstructural Properties}

The dispersion and surface bonding of the reinforcing solid phase with the polymer matrix affects many important characteristics; such as mechanical properties and dimensional stability [13] [15]. Therefore; it is important to review the reinforcing phase-matrix interface and the distribution of the filler within the matrix in order to explain the characteristic behavior of these composites. SEM micrographs of pristine PVC foam and the PVC foam composites reinforced with mica are shown in Figures 9(a)-(e).

The micrograph of the sample reinforced with 5\% mica shows good dispersion of mica in the PVC foam matrix (Figure 9(b)). In addition, one can also observe the lamellar structure of mica and its orientation parallel to the cell walls within the foam matrix. This is an indication of good bonding between the mica platelets and the 

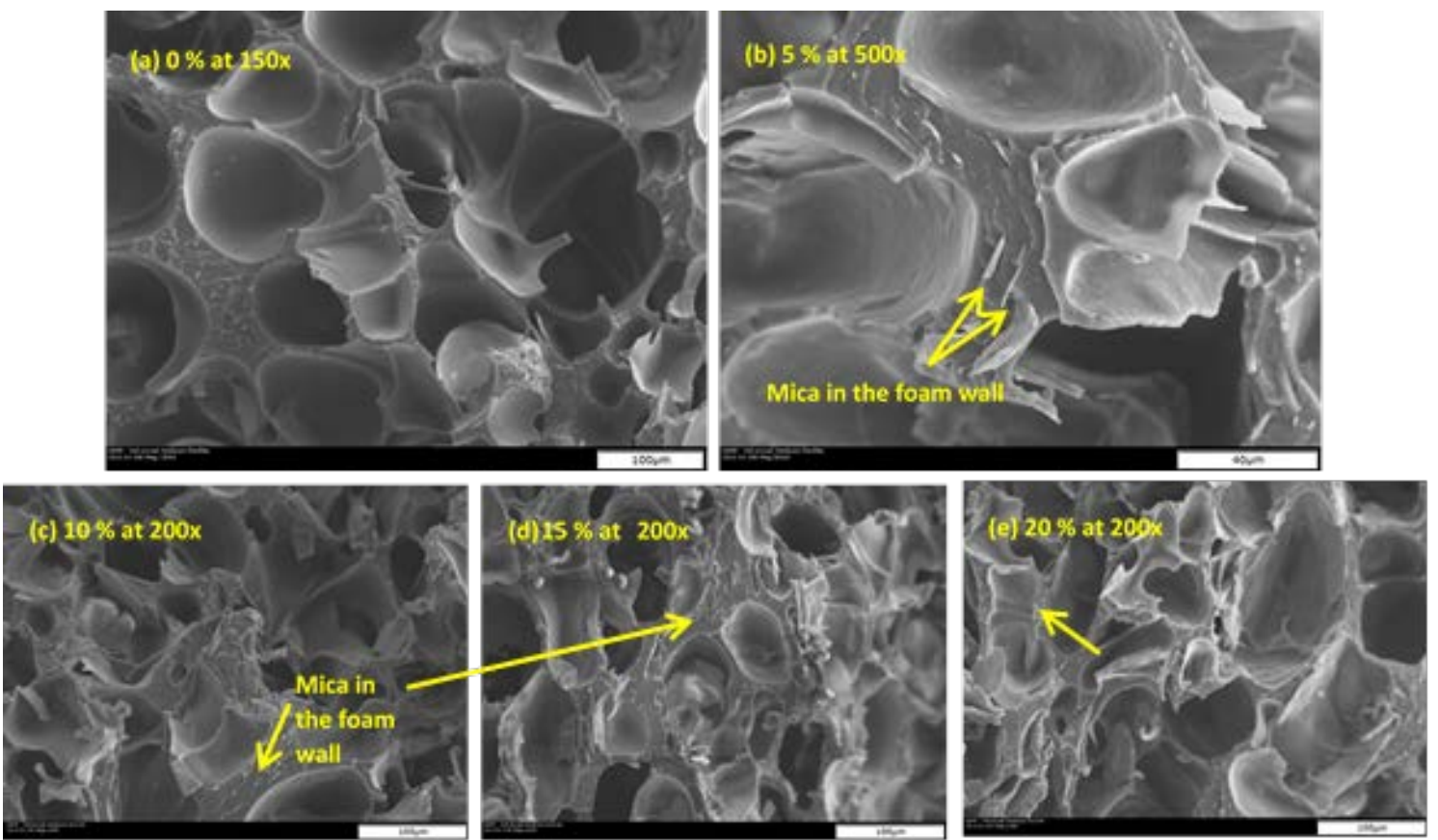

Figure 9. SEM micrographs of PVC-mica foam composites at: (a) $0 \%$, (b) $5 \%$, (c) $10 \%$, (d) $15 \%$, and (e) $20 \%$ mica.

PVC foam matrix, which partially explains the improvements in dimensional stability and mechanical properties of the composites. The micrographs also show that the dispersion of mica in the foam matrix was random up to a loading of $15 \%$, and the orientation of mica was mostly parallel within the cell walls. However, in samples containing 20\% mica (Figure 9(e)), some of the mica platelets seem to have agglomerated in the foam walls. This supports the discussion on the anomaly observed in the viscoelastic and mechanical properties of the PVC-mica foam composites.

\section{Conclusions}

The lamellar structure of the mica flakes combined with their preferred orientation along the cell walls improved their surface bonding with the polymer matrix. This led to a significant improvement in the dimensional stability of the PVC composites and it was proportional to the concentration of mica in the composite. In addition, the viscoelastic properties of the composites measured by the storage and loss moduli were found to be optimum at a concentration of $15 \%$ mica, whereas the tensile strength and ductility were optimum at a concentration of $10 \%$ mica in the composites. These properties were found to deteriorate at higher concentrations of mica due to particle agglomeration in the cell walls. The addition of mica up to $20 \%$ in the composites did not change the flexural strength significantly, although it resulted in over $25 \%$ reduction in the impact strength as the rigidity of the composites increased.

SEM images of the cellular structure confirmed higher dispersion of the mica flakes at lower concentrations $(<15 \%)$, and a tendency for agglomeration at higher concentrations $(>15 \%)$. In addition, SEM images confirmed that the orientation of the mica flakes was parallel to the cell walls which resulted in better surface bonding with the polymer phase. However, at higher concentrations, the mica particles seemed to agglomerate in the cell walls forming separate brittle solid phases, which seemed to lower the surface bonding with the polymer phase.

\section{References}

[1] Shen, L., Haufe, J. and Patel, M. (2009) Product Overview and Market Projection of Emerging Bio-Based Plastics. Report, Utrecht University, Utrecht.

[2] Lee, S., Park, C. and Ramesh, N. (2007) Polymeric Foams. CRC Press, Boca Raton, 8-21.

[3] British Plastic and Rubber (2003) Mineral Fillers for PVC Reinforcement. 4-6.

[4] Jiang, H. and Kamdem, D. (2004) Development of Poly(vinyl chloride)/Wood Composites. A Literature Review. 
Journal of Vinyl and Additive Technology, 10, 59-69. http://dx.doi.org/10.1002/vnl.20009

[5] Borda, J., Deák, G., Zsuga, M., Marossy, K., et al. (2012) Preparation and Characterization of Poly(vinyl chloride)Continuous Carbon Fiber Composites. Journal of Applied Polymer Science, 124, 190-194. http://dx.doi.org/10.1002/app.33617

[6] Phlogopite Mica. http://www.lkabminerals.com/en/Minerals/Phlogopite-Mica/

[7] Xanthos, M. (2010) Functional Fillers for Plastics. 2nd Edition, John Wiley \& Sons, Hoboken, 14-16. http://dx.doi.org/10.1002/9783527629848

[8] Zhao, R., Huang, J., Sun, B., et al. (2001) Study of the Mechanical Properties of Mica-Filled Polypropylene-Based GMT Composite. Journal of Applied Polymer Science, 82, 2719-2728. http://dx.doi.org/10.1002/app.2124

[9] Raj, R., Kokta, B. and Daneault, C. (1990) Comparative Study on the Effect of Aging on Mechanical Properties of LLDPE-Glass Fiber, Mica, and Wood Fiber Composites. Journal of Applied Polymer Science, 40, 645-655. http://dx.doi.org/10.1002/app.1990.070400502

[10] Liang, J. and Yang, Q. (2007) Mechanical, Thermal, and Flow Properties of HDPE-Mica Composites. Journal of Thermoplastic Composite Materials, 20, 225-236. http://dx.doi.org/10.1177/08927057074592

[11] Canova, L.A., Ferguson, L.W., Parrinello, L.M. and Subramanian, R. (1997) Effect of Combinations of Fiber Glass and Mica on the Physical Properties and Dimensional Stability of Injection Molded Polypropylene Composites. Proceedings of 55th Annual Technical Conference Society of Plastics Engineering, 2, 2112-2116.

[12] Souza, D.H.S., Andrade, C.T. and Dias, M.L. (2014) Effect of Synthetic Mica on the Thermal Properties of Poly(lactic acid). Journal of Polímeros: Ciência e Tecnologia, 24, 20-24.

[13] Sreekanth, M.S., Bambole, V.A., Mhaske, S.T. and Mahanwar, P.A. (2009) Effect of Concentration of Mica on Properties of Polyester Thermoplastic Elastomer Composites. JMMCE, 4, 271-282.

[14] Marshall, C., Rozett, R. and Kunkle, A. (1985) Effect of Mica as a Filler in Polypropylene, HDPE, and PVC, SPI. Reinforced Plastics/Composites Inst, New York.

[15] Jiang, H.H. and Kamdem, D.P. (2004) Development of Poly(vinyl chloride)/Wood Composites. A Literature Review. Journal of Vinyl and Additive Technology, 10, 59-69.

[16] Deshmukh, S.P., Rao, A.C., Gaval, V.R. and Mahanwar, P.A. (2011) Mica-Filled PVC Composites: Effect of Particle Size, Filler Concentration, and Surface Treatment of the Filler, on Mechanical and Electrical Properties of the Composites. Journal of Thermoplastic Composite, 24, 583-599.

[17] Wang, G.Q. and Chen, Y.T. (1991) Test Methods for Gelation of PVC Plastisol. Polymer Testing, 10, 315-324. http://dx.doi.org/10.1016/0142-9418(91)90025-S

[18] Pytel, A. and Singer, F. (1987) Strength of Materials. 4th Edition, Harper \& Row Publishers, New York.

[19] Lu, H.G., Purushothama, S., Hyatt, J., Pan, W.-P., Riley, J.T., Lloyd, W.G., et al. (1996) Co-Firing High-Sulfur with Refuse-Derived Fuel. Thermochimica Acta, 284, 161-177. http://dx.doi.org/10.1016/0040-6031(96)02864-X

[20] Khoshnoud, P., Gunashekar, S., Jamel, M.M. and Abu-Zahra, N. (2014) Comparative Analysis of Rigid PVC Foam Reinforced with Class C and Class F Fly Ash. Journal of Minerals and Materials Characterization and Engineering, 2, 554-565. http://dx.doi.org/10.4236/jmmce.2014.26057

[21] Qiao, J., Amirkhizi, A.V., Schaaf, K. and Nemat-Nasser, S. (2010) Dynamic Mechanical Analysis of Fly Ash Filled Polyurea Elastomer. Journal of Engineering Materials and Technology, 133, 011016-011016-7.

[22] Collocaa, M., Dorogokupetsa, G., Guptaa, N. and Porfiri, M. (2012) Mechanical Properties and Failure Mechanisms of Closed-Cell PVC Foams. International Journal of Crashworthiness, 17, 327-336. 